\title{
AULAS DE CIÊNCIAS NA OITAVA SÉRIE DO ENSINO FUNDAMENTAL: UMA PROPOSTA DE PROJETO CURRICULAR COMO PROCESSO EM CONSTRUÇÃO
}

\author{
Science classes in the eighth year \\ of Elementary Education: a curricular project proposal \\ as a process under construction
}

\author{
Daniela Rodrigues da Silva ${ }^{1}$ \\ José Del Pino ${ }^{2}$
}

\begin{abstract}
Resumo: Este artigo apresenta o planejamento e desenvolvimento de um projeto curricular construído enquanto processo, com o intuito de organizar estratégias metodológicas, entre elas a resolução de problemas, e completar, assim, uma proposta pedagógica com pressupostos construtivistas. A pesquisa foi realizada com uma turma de oitava série do Ensino Fundamental, na disciplina de ciências. A participação de um professor pesquisador, capaz de realizar a interlocução entre teoria e prática, e o diálogo entre professora e alunos tornaram-se elementos determinantes para a estruturação do projeto curricular, buscando a abordagem de conceitos científicos ao mesmo tempo em que necessidades e interesses do grupo em estudo pudessem ser debatidos. A interação em sala de aula e as produções dos alunos, a partir das estratégias utilizadas, foram componentes de análise e discussão para direcionar o desenvolvimento da proposta, e modificaram o comportamento e os hábitos dos sujeitos envolvidos no processo.
\end{abstract}

Palavras-chave: Ensino de Ciências. Currículo de Ciências. Interação. Pesquisa em Ensino de Ciências. Educação Básica.

\begin{abstract}
This paper presents the planning and development of a curricular project built as a process, with the intention of organizing the methodological strategies used, like problem solving, and to fulfill a pedagogic proposal in a constructivist approach. The research was carried out with an eighth year Elementary Education science class. The participation of a teacher-researcher capable of making the interlocution between theory and practice, and the dialogue between teacher and students, turned out to be determining elements to structure the curricular project, searching for a scientific concepts' approach, at the same time that the needs and interests of the group could be discussed. The classroom interaction and the students' productions, from the strategies used, were analysis and discussion components in order to guide the proposal development, and they modified the behavior and habits of the subjects engaged in the process.
\end{abstract}

Keywords: Science teaching. Science school curriculum. Interaction. Science education research. Basic education.

${ }^{1}$ Licenciada em Ciências Habilitação em Química, mestre em Educação em Ciências. Docente, Instituto Federal do Rio Grande do Sul, campus Canoas. Canoas, RS, Brasil. < dani.santoro@hotmail.com>

${ }^{2}$ Licenciado e doutor em Química. Docente, Departamento de Química Inorgânica, Instituto de Química, Universidade Federal do Rio Grande do Sul. Porto Alegre, RS, Brasil. < delpinojc@yahoo.com.br>

${ }^{1}$ Rua Dra. Maria Zélia Carneiro de Figueiredo, 870

Bairro Igara III - Canoas, RS

$94.412-240$

447

Ciência : Ed Educação, v. 16, n. 2, p. 447-464, 2010 
Silva, D. R.; Pino, J. D.

\section{Introdução}

A necessidade de elaboração de um projeto curricular diferente do tradicionalmente utilizado nas escolas é consequência de uma série de problemas que são sustentados e se agravam na medida em que os alunos não encontram significado nas aulas que são obrigados a frequentar.

As tentativas realizadas para modificar o ensino que é praticado nas escolas, geralmente, acontecem a partir de determinações pensadas fora destas instituições de ensino, por um grupo de pessoas que não conhecem a realidade das escolas públicas, que elabora "receitas" para serem seguidas por todos e que, até hoje, não resolveram os problemas da Educação Básica, pois não condizem com a realidade que é vivenciada no contexto escolar.

Para que um novo projeto curricular se efetive e modifique realmente a situação da Educação Básica, acredita-se que este deve ser construído com contribuições dos sujeitos que estão na escola onde o projeto será desenvolvido. Mas, para que isso aconteça, pressupõe-se também um novo professor, ativo, pesquisador, reflexivo, que não se satisfaz como mero executor de propostas pensadas fora da escola, e que confia no potencial do seu trabalho, para com suas ações ajudar a construir novos alunos, críticos, solidários, participativos e que terão maiores possibilidades de se tornarem cidadãos atuantes no contexto social fora da escola.

Assim, este trabalho apresenta o planejamento e desenvolvimento de um projeto curricular enquanto processo construído em conjunto, por professor e alunos, que, na açãoreflexão-ação, buscaram a qualificação dos processos de ensino e aprendizagem, no complexo contexto da sala de aula.

Entre os diferentes aspectos possíveis envolvidos na discussão da construção para a proposição do projeto curricular, optou-se por uma proposta, que atendesse aos objetivos da pesquisa, almejando-se a organização de estratégias metodológicas, como a resolução de problemas, por exemplo, de forma a analisar os processos que envolvem o ensinar e o aprender, como uma alternativa diferente da tradicionalmente desenvolvida nas escolas.

\section{Um novo professor}

A tomada de consciência sobre os problemas enfrentados e vivenciados pelos sujeitos do ambiente escolar permite compreender a necessidade de que mudar a prática pedagógica atual requer uma série de decisões vinculadas, entre outras, a construção de uma nova forma de planejar e desenvolver esta prática, reconstruindo relações e conceitos a respeito dos processos envolvidos no projeto curricular.

Ao invés de ficar à espera de novas determinações vindas de fora do contexto escolar - e que, até hoje, não conseguiram atingir de forma concreta a escola básica -, o professor, enquanto sujeito que não se conforma com os resultados ineficientes de aprendizagem obtidos pelo seu trabalho, precisa refletir sobre o seu papel e as possibilidades que tem para iniciar, na prática, as mudanças capazes de melhorar esse sistema do qual faz parte e também é responsável.

Sabe-se, no entanto, que há uma série de características que mantém o professor passivo diante da realidade vivenciada nas escolas hoje, tornando-o um mero executor, que 
cumpre determinações externas e não reflete sobre o seu fazer, para compreendê-lo e modificá-lo. Entre estas características, pode-se citar a elevada carga horária a que o professor se submete para sobreviver, impossibilitando a busca por qualificação por meio da formação continuada e da pesquisa, reforçando, dessa forma, outra característica, a utilização do livro didático como única possibilidade para organização das aulas.

De acordo com Loguercio et al. (2007, p. 15),

Inseridos numa cultura de, no mínimo, um século de utilização de livros-textos e de conteúdos impostos por outras culturas somados à desautorização dos professores para gerirem suas práticas pedagógicas é, realmente, muito difícil para o professorado considerar a possibilidade de que esses conteúdos possam não ser os mais indicados para as suas realidades escolares.

Além disso, as limitações resultantes de determinações administrativas e políticas impostas por quem está fora do ambiente escolar interferem diretamente nas ações dos sujeitos dentro da escola. Assim, com professores sem tempo e incentivo para qualificação, envolvidos em um contexto que limita suas ações, o sistema de ensino da Escola Básica vai perpetuando as formas tradicionais de atuação.

Mesmo iniciativas mais amplas, como a dos Parâmetros Curriculares Nacionais de Ciências Naturais (PCNs-CN) já propostos há mais de cinco anos, não conseguem superar as práticas correntes no ensino e educação em Ciências: conteúdos estanques e fragmentados, longe do contexto. Se eventualmente, são trabalhados determinados temas fora da proposta original de um programa de ensino, isso permanece como mera inserção pontual. Terminada a discussão do tema, volta-se ao mesmo ponto, dando seguimento ao programa tradicional de ensino. (MALDANER e ZANON, 2004, p. 48)

No entanto, mesmo diante destes obstáculos presentes no dia-a-dia do professor de escola pública, acredita-se que um fazer diferente é possível, desde que permeado pela compreensão do que se pretende atingir. Inovar, pelo simples fato de modificar a prática com base em uma "receita" indicada por outros, que provavelmente desconhecem o contexto de trabalho no qual o projeto será desenvolvido, possivelmente não será solução para os problemas com os quais convivem os sujeitos envolvidos com o sistema de ensino atual. Porém, a busca pela interlocução entre teoria e prática permitirá um fazer inovador, que se justifica pela necessidade de mudança do que está posto, com o intuito de encontrar soluções que satisfaçam as necessidades diagnosticadas no dia a dia escolar. Para Arroyo (1999, p. 145), "temos de rever nossa tradição político pedagógica, que divide o sistema escolar em três campos - os que decidem, os que pensam e os que fazem educação - e que, com base nessa divisão, espera que a inovação educativa ocorra a partir dos que decidam e pensam".

Sabe-se que pensar novas formas de agir buscando estratégias metodológicas que possibilitem essas inovações, de acordo com pressupostos teóricos significativos para o pro- 
Silva, D. R.; Pino, J. D.

fessor, não é uma tarefa simples ou fácil. Em meio à complexidade de ações que envolvem o contexto escolar, o professor precisa entender-se como um dos sujeitos envolvidos no processo de reconstrução deste ambiente considerado "fracassado", e que também precisa rever seus conceitos e formas de atuação, aceitando-se como inacabado e em processo constante de aprendizagem, assim como seus alunos.

Freire (2000, p. 58), ao ressaltar a importância da consciência do inacabamento, pelo professor, no processo de ensino, afirma:

Gosto de ser homem, de ser gente, porque sei que a minha passagem pelo mundo não é predeterminada, preestabelecida. Que o "meu” destino não é um dado, mas algo que precisa ser feito e de cuja responsabilidade não posso me eximir. Gosto de ser gente porque a História em que me faço com os outros e de cuja feitura tomo parte é um tempo de possibilidades e não de determinismo.

Ao optar por utilizar a autonomia profissional que ainda lhe resta para reconstruir o seu projeto curricular, o professor escolhe passar por sensações de desconforto e insegurança, na medida em que este terá de trilhar caminhos novos, desconhecidos e que ele mesmo irá descobrir e construir por meio de sua prática. No entanto, segundo Freire (2000, p.43), "é pensando criticamente a prática de hoje ou de ontem que se pode melhorar a próxima prática"; assim, o professor compreenderá que é no meio dessas sensações que o seu trabalho torna-se interessante e significativo.

\section{Um novo projeto curricular a partir de um novo professor}

Construir um novo projeto curricular, ou seja, planejar e desenvolver uma prática na interlocução com pressupostos teóricos que a tornem significativa, com o intuito de qualificar os processos de ensino e aprendizagem, requer a tomada de consciência, por parte do professor, sobre quais são os problemas vivenciados no projeto curricular tradicionalmente desenvolvido. Para Silva (1999, p. 13), "na visão tradicional, o currículo é pensado como um conjunto de fatos, de conhecimentos e de informações, selecionados do estoque cultural mais amplo da sociedade, para serem transmitidos às crianças e aos jovens".

Ampliar esta visão tradicional possibilita ao professor pensar novas formas de planejar e desenvolver suas ações. De acordo com Gimeno Sacristán (2000, p. 173),

O currículo é muitas coisas ao mesmo tempo: idéias pedagógicas, estruturação de conteúdos de uma forma particular, detalhamento dos mesmos, reflexo de aspirações educativas mais difíceis de moldar em termos concretos, estímulo de habilidades nos alunos, etc. Ao desenvolver uma prática concreta de modo coerente com quaisquer desses propósitos, o professor desempenha um papel decisivo.

Por isso, acredita-se que construir um novo projeto curricular está diretamente vinculado à necessidade de um novo professor, com competências profissionais mais amplas, que 
vão além do domínio do conteúdo específico e de sua transmissão. Um novo professor, neste contexto, significa: um profissional que dá a devida importância ao seu fazer; que busca, na reflexão, um diálogo entre a teoria e a prática; que pesquisa para tornar-se capaz de analisar a realidade em que trabalha, com o intuito de planejar ações para melhorá-la, se reconstruindo professor na medida em que se constrói pesquisador. Conforme Silva (1999, p.27), “o currículo está centralmente envolvido naquilo que somos, naquilo que nos tornamos, naquilo que nos tornaremos. O currículo produz, o currículo nos produz".

$\mathrm{Na}$ medida em que a visão tradicional de currículo, focada no livro didático e na sua sequência a partir da transmissão de conceitos, vai sendo substituída por outra visão mais ampla, o professor precisa definir quais serão os pressupostos teóricos e práticos que constituirão o planejamento e o desenvolvimento do seu projeto curricular e que sustentarão a sua proposta pedagógica. Para a organização deste trabalho, agora apresentado, foram considerados vários aspectos que estão diretamente vinculados a um projeto curricular enquanto processo em constante construção.

Entende-se que o planejamento curricular não compreende apenas a definição dos conteúdos que serão abordados durante o ano letivo, sua sequência e forma de avaliação, mas sim um processo muito mais amplo que envolve a organização de diferentes situações em um ambiente complexo e rico em possibilidades.

Como um processo, o planejamento e desenvolvimento curricular estão sempre interligados como um projeto que se completa e define-se dia após dia, relacionando teoria e prática, de acordo com o que é vivenciado e compreendido com base nas análises realizadas pelo professor e que buscam atingir as necessidades e interesses do grupo. Por isso, o contexto tem muito a dizer e precisa ser considerado, na medida em que fornece elementos importantes para que o projeto seja significativo para todos os sujeitos envolvidos. De acordo com Gimeno Sacristán e Pérez Gómez (1998, p. 148), o currículo

trata-se de um projeto que só pode ser entendido como um processo historicamente condicionado, pertencente a uma sociedade, selecionado de acordo com as forças dominantes nela, mas não apenas com capacidade de reproduzir, mas também de incidir nessa mesma sociedade.

Assim, planejar o currículo considerando o contexto em que ele será desenvolvido torna-se um exercício de análise constante da realidade vivenciada, de suas características, aspectos positivos e negativos, para que o professor possa elaborar estratégias metodológicas de ensino que venham a interferir nessa realidade, a fim de melhorá-la, como resultado de ações realizadas pelos próprios sujeitos que a compõem.

A ação do aluno é fundamental para o desenvolvimento do projeto curricular, na medida em que fornece elementos importantes para o seu planejamento. É por meio da ação do aluno que o professor terá informações para conhecer suas características socioafetivas e cognitivas, podendo elaborar atividades que sejam significativas e adequadas para favorecer a aprendizagem.

Para Schultz e Parhan (2002, p. 206),

Nos últimos cinqüenta anos as teorias de aprendizagem têm desempenhado um papel cada vez mais importante para o desenvolvimento do 
Silva, D. R.; Pino, J. D.

currículo. Porém, estas teorias têm afetado, sobretudo a maneira como se ensina as matérias tradicionais, sem conduzir a uma reconsideração sobre se estas matérias constituem áreas de conhecimento adequado para as crianças.

Por isso, estar atento às produções dos alunos, seus temas de interesse, suas concepções iniciais a respeito dos conceitos que serão trabalhados, seus comportamentos e atitudes, e todos os acontecimentos nos quais eles estão envolvidos no contexto escolar, torna-se, para o professor, um meio de pesquisa para encontrar elementos que possibilitem aos alunos participarem da construção do currículo. Este processo que envolve a construção conjunta entre professor e alunos vai delimitando o que precisa ser abordado e como essa abordagem facilitará a participação ativa de todos.

Segundo Porlán, (1998, p.153),

é importante que decidamos quais são os nossos objetivos, porém também é importante que não permaneçamos atrapalhados por eles, que admitamos sua relatividade, sua possível evolução e, sobretudo, sua necessária reformulação à luz dos interesses e necessidades dos alunos.

Entende-se, assim, que cada planejamento curricular é único e justifica-se na medida em que vai sendo desenvolvido e significado por aquele grupo que o compõe. Por isso, os sujeitos que compõem a sociedade escolar precisam iniciar um exercício de análise das propostas que são enviadas pelo governo para serem executadas, buscando desenvolver a criticidade para adaptá-las da melhor forma para aquele contexto em que convivem, analisando suas intenções e construindo alternativas para desenvolvê-las visando facilitar os processos de ensino e aprendizagem. Esses mesmos sujeitos devem divulgar os resultados das ações e reflexões realizadas por meio desta interlocução entre o que é imposto e o que é criado, para que estas novas alternativas de projetos curriculares sejam reconhecidas e consideradas por aquelas pessoas que interferem e limitam o funcionamento das escolas sem ao menos conhecê-las.

\section{$O$ contexto da pesquisa}

A escola na qual o projeto curricular foi planejado e em que a pesquisa foi desenvolvida é de Ensino Fundamental, com séries iniciais e finais nos turnos da manhã e tarde, e com educação de jovens e adultos no turno da noite. Nas séries iniciais há uma única professora regente para cada série, e, nas séries finais, os alunos começam a conviver com vários professores, cada um responsável pelo seu componente curricular específico, com um número determinado de horas-aula semanais, metodologias semelhantes, avaliações adequadas ao regimento escolar, poucos recursos materiais, além do quadro-negro, giz ou livro didático.

Dentro desse sistema comum a todas as escolas da mesma rede pública, não há espaço para que os professores elaborem seus planejamentos curriculares ou metodologias, projetos, enfim, ações em grupo. A organização curricular não contempla, na sua carga horária, um momento para que os professores possam se encontrar e construir, em conjunto, um projeto curricular que atenda às necessidades daquela comunidade escolar. 
Como resultado, cada professor age de acordo com as suas concepções e do que considera mais apropriado para os grupos de alunos com que trabalha, cumprindo sua carga horária, e compartilhando suas angústias com os colegas no intervalo do recreio, ou em um único momento de encontro trimestral, que constitui o conselho de classe, quando são apresentados os desempenhos alcançados pelos alunos nas diferentes disciplinas naquele trimestre específico.

Ao mesmo tempo em que se vivencia um sentimento de impotência diante de tal situação, acredita-se que não é possível acomodar-se com tal realidade e entrar no ritmo desse sistema tão incoerente, sobretudo porque é preciso ter consciência de que a escola é, para muitas crianças, a única possibilidade de socialização e contato com a cultura, especialmente a escola pública, que atende às crianças mais carentes e desassistidas tanto pelas famílias quanto pela sociedade.

Por isso, inquieta com a realidade da qual participa enquanto professora da escola pública, a autora deste trabalho procurou, por meio da pesquisa, uma forma de modificar a sua prática, na busca de soluções para os problemas que fazem parte do seu dia a dia no contexto escolar, mais especificamente, nas aulas de ciências pelas quais é responsável.

Imerso no contexto da escola pública estadual, o presente trabalho é resultado de um estudo de caso realizado com a $8^{a}$ série do Ensino Fundamental, na disciplina de ciências, no turno da manhã de uma escola situada na cidade de Porto Alegre, RS. Realiza-se, neste texto, uma análise dos processos de planejamento ao longo do desenvolvimento curricular, enquanto processo em constante construção, com o intuito de investigar as estratégias metodológicas e utilizar os seus resultados no desenvolvimento de uma nova proposta pedagógica com pressupostos construtivistas de acordo com um novo projeto curricular.

A turma em estudo era composta por trinta alunos, oriundos de diferentes bairros da capital gaúcha - pois a escola situa-se próxima a uma avenida de fácil acesso -, provenientes de famílias de classe média-baixa ou baixa, e que, na sua maioria, já frequentava a escola desde as séries iniciais. A professora titular da disciplina e pós-graduanda desenvolveu a pesquisa durante todo o ano letivo de 2007, com carga horária de três horas/aula, sem abandonar seu regime de trabalho de quarenta horas/aula semanais, pelo qual é nomeada na rede pública estadual.

Objetivando vincular teoria e prática para buscar soluções para os problemas vivenciados no contexto da escola pública, a professora planejou e aplicou, aula após aula, uma proposta pedagógica, com o uso de estratégias metodológicas diversas, justificadas por um planejamento curricular flexível e contextualizado com a realidade em estudo. Assim, apresentam-se, a seguir, os elementos que compuseram o planejamento curricular desta proposta.

\section{Projeto curricular - coleta e análise de dados}

Tecer uma proposta pedagógica estruturada por um projeto curricular diferenciado é tão desafiador quanto fascinante. Para o professor, a proposição de um currículo diferente daquele com o qual está acostumado gera insegurança e, consequentemente, a exigência de estudo e reflexão, para que as escolhas sejam fundadas e atendam às necessidades dos alunos.

A análise do contexto em estudo a partir de subsídios teóricos, o diálogo constante com o orientador e o cuidado com as limitações impostas pelo sistema escolar, possibilitaram 
Silva, D. R.; Pino, J. D.

a elaboração de um projeto curricular flexível e significativo, tanto para os alunos quanto para a professora.

O planejamento curricular esteve vinculado, durante todo o ano letivo, às necessidades e aos interesses dos alunos, que, durante o desenvolvimento da proposta, possibilitaram, por meio de ações e da pesquisa constante da professora, escolher: os conceitos fundamentais de referência, habilidades, valores, atitudes relacionadas ao comportamento do grupo, e que precisavam ser trabalhados objetivando novas situações de ensino e aprendizagem.

Todo o processo foi desenvolvido com base em um planejamento complexo de estratégias, visando um trabalho integrado e contínuo, evitando-se a forma linear e fragmentária, como geralmente os livros didáticos propõem a implementação de assuntos do cotidiano, com a formação de dois momentos, um de estudo de conteúdos importantes e específicos da disciplina, que serão avaliados em prova, e outro da "curiosidade", no qual o professor explicaria, a partir de um texto ou demonstração prática, alguma situação mais próxima da realidade dos alunos e que estivesse vinculada aos conceitos ensinados. Segundo Porlán (1998, p .164),

o processo de ensino-aprendizagem não deve ser um reflexo mecânico do planejamento do professor nem tampouco um reflexo simplista da espontaneidade dos alunos [...] deve ser o resultado de integrar de forma natural as intenções educativas do professor (expressas como hipóteses sobre o conhecimento escolar desejável) e os interesses refletidos e organizados dos estudantes (expressos como problemas a investigar na classe).

Desse modo, acredita-se que há necessidade de se construírem hipóteses sobre uma série de conceitos que precisam ser estudados, e que, portanto, direcionarão os planejamentos caracterizando a intencionalidade da proposta; mas a real definição dos conteúdos e conceitos específicos deve acontecer durante o ano letivo, na interação entre alunos e professor. Segundo Collares (2003, p. 92), "na dimensão construtivista piagetiana, as ações dos alunos e dos professores definem os caminhos a serem trilhados. Ou seja, o docente, ao agir como investigador, construirá hipóteses e seguirá as construções do(s) aluno(s), sem abandonar ou impor as suas".

Retoma-se, assim, a ideia de que um projeto pedagógico diferente do tradicional, que é tecido com base em um planejamento curricular diferenciado, exige um novo professor, que não conseguirá se transformar do dia para a noite, como resultado de sua boa intenção em fazer o melhor, mas que se reconstruirá a partir da própria prática e da pesquisa que realiza ao analisar seus alunos e a si mesmo, diante das incertezas e do compromisso assumido em fazer da sua prática de ensino um ambiente de aprendizagem.

Por isso, dizer que o currículo estrutura-se a partir de temas de interesse escolhidos pelos alunos não significa realizar um único diagnóstico no início do ano letivo e, assim, definir uma proposta para o ano inteiro. O diagnóstico inicial é importante na medida em que apresenta alguns temas considerados interessantes pelos alunos, ajudando o professor a começar a conhecer as características daquele grupo, e, ao mesmo tempo, faz com que os alunos percebam que a proposta que será desenvolvida é diferente das tradicionalmente trabalhadas e com as quais eles estão acostumados. Porém entende-se que a pesquisa na forma de diagnóstico precisa continuar durante todo o ano para que as informações coletadas, a cada etapa do 
Aulas de Ciências na oitava série ...

processo, permitam ao professor uma análise constante da realidade dos alunos, suas necessidades e interesses.

Respeitar as necessidades e interesses dos alunos significa estar-se atento às suas ações e à forma como os mesmos as desenvolvem para, a partir daí, intervir com propostas que os acompanhem e desafiem-nos a pensar sobre aquilo que parece afeta-los e interessá-los, atendendo a natureza afetiva (o móvel ou energético) e a natureza cognitiva (as estruturas de transformação) de suas ações. (COLLARES, 2003, p. 204)

O planejamento curricular e seu desenvolvimento são processos em construção constante nesta abordagem, pois, definiram-se ao longo do ano, como resultado de uma pesquisa contínua das características daquele grupo. Da mesma forma, buscando elaborar estratégias de ação significativas para os alunos, a compreensão de suas concepções e conhecimentos iniciais a respeito dos conceitos ou assuntos que seriam abordados tornou-se elemento fundamental para se definirem as relações seguintes que seriam tecidas.

Conforme Schultz e Parhan (2002), em uma situação escolar, é fácil enganar-se pensando que os alunos entendem todo tipo de ideias que, na realidade, não entendem. Para realizar uma aprendizagem verdadeira, eles devem contar com suas próprias estruturas e mecanismos de validação que, com toda certeza, vão sendo reconstruídos durante o desenvolvimento.

Com base na investigação dos conhecimentos dos alunos, buscou-se elaborar atividades adequadas ao grupo de estudo, e identificar características particulares de cada um, para que o professor pudesse acompanhar adequadamente: as construções que iam acontecendo a partir de suas intervenções e das problematizações desenvolvidas em aula; se havia ou não necessidade de retomadas; como deveria ser a organização dos grupos para que os alunos pudessem cooperar uns com os outros durante as atividades, entre outros indicativos importantes para que o processo de construção continuasse. "Aprender num sentido reconstrutivo é avançar em direção ao desconhecido a partir do já sabido. Aprender é reconstruir o conhecimento existente, tornando-o mais complexo"(MORAES, 2004, p. 25).

Considerando que as estratégias metodológicas utilizadas para esta proposta de ensino exigiam a participação ativa dos alunos, e que a elaboração das atividades estava diretamente vinculada aos resultados destas ações, o acompanhamento constante por parte do professor foi fundamental, entre outros aspectos, no fornecimento de informações que possibilitassem o planejamento de atividades condizentes com a realidade dos alunos, pois se acredita que estratégias metodológicas elaboradas a partir de concepções dos professores nem sempre resultarão em atividades significativas para os alunos.

Da mesma forma, considera-se que o desenvolvimento de propostas planejadas fora do contexto escolar, indiferentes às características do grupo de trabalho - e que, como "receitas" a partir de currículos determinados e rígidos, são indicadas como propostas inovadoras, para serem executadas pelos professores, que se tornam assim executores, e não construtores - , contribuem para reafirmar a escola como um lugar ultrapassado e sem sentido para os alunos. Por isso, o planejamento e desenvolvimento curricular precisam ser pensados na instituição de ensino, como um processo de construção, que não acontece imediatamente, a partir de uma determinação externa. 
Silva, D. R.; Pino, J. D.

Para Arroyo (1999, p. 155),

A educação escolar não acontece por descontinuidades, como se, antes do treinamento, antes dos PCN ou antes do pensamento crítico, tivéssemos currículos atrasados e, depois deles, a renovação curricular. Não é assim. A educação acontece em uma trama de continuidades de práticas, valores, procedimentos, rituais, saberes e culturas. È aí que a inovação educativa vai sendo tecida.

Assim, a apresentação dos conteúdos, conceitos específicos e atividades desenvolvidas durante um ano letivo inteiro não tem significado se estes não forem apresentados em conjunto com o contexto para o qual foram pensados e construídos, pois "qualquer que seja o projeto que se tenha para a escola, seu significado real e seu valor está nas ações que o origina, em função do contexto metodológico e institucional em que se desenvolve" (GIMENO SACRISTÁN e PÉREZ GÓMEZ, 1998, p. 145).

A escola em que a pesquisa foi desenvolvida apresenta, como plano de estudo para o componente curricular de ciências, para a $8^{a}$ série do Ensino Fundamental, o conteúdo "tecnologia e saúde", objetivando "oportunizar o conhecimento científico de forma precisa e sintética sobre o mundo natural e tecnológico na busca de novas respostas e desafios". Não havia uma lista de conteúdos a serem desenvolvidos em uma ordem específica, cabendo ao professor a definição da melhor proposta para o grupo de alunos de cada turma.

Ao iniciar o planejamento curricular, a professora elaborou um questionário com o intuito de conhecer: quais eram as atividades diárias dos alunos no período em que estavam fora da escola; o que estes pensavam a respeito da escola; com quem moravam e como era o relacionamento com seus familiares; quais as concepções que estes tinham sobre a ciência; quais os objetivos e sonhos para o futuro, e quais eram os temas de interesse que eles gostariam de estudar durante o ano letivo na disciplina de ciências. Este questionário permitiu à professora ter uma visão inicial das principais características daquele grupo com o qual iria trabalhar e a indicação dos temas gerais que iriam constituir o projeto curricular: esportes, corpo humano e doenças.

É importante ressaltar que a professora não conhecia o grupo em estudo, pois este foi o seu primeiro ano nesta escola, como resultado da reorganização do quadro de professores realizada pelo governo estadual no início do ano letivo de 2007. A professora foi transferida para esta escola no final de março, quando o ano letivo já havia começado e, portanto, as primeiras semanas de contato também foram de reconhecimento do contexto em que a pesquisa seria desenvolvida.

Com os resultados do questionário, realizou-se um debate em sala de aula para definir quais as dúvidas e o que mais interessava aos alunos quando estes indicaram os temas esportes, corpo humano e doenças. Percebeu-se uma grande preocupação, tanto dos meninos quanto das meninas, com a boa aparência física, a busca de corpos "sarados" - e a aula de educação física como a mais interessante e o momento mais esperado durante a semana, dia em que ninguém faltava, pois podiam sair da sala de aula e praticar diferentes esportes, especialmente o futebol. Ao mesmo tempo, demonstraram ter hábitos alimentares pouco saudáveis, com o consumo exagerado de refrigerantes e alimentos industrializados, como salgadinhos e bola- 
chas recheadas, que serviam, inclusive, como café da manhã no intervalo do recreio. Relataram situações em que colegas passavam mal na escola por não tomarem café da manhã e afirmaram que muitos realizavam a primeira refeição apenas no horário do almoço.

Como resultado deste momento, identificou-se um grupo que entendia as atividades esportivas como momento de demonstração de poder e de exposição do corpo, sem a compreensão da relação corpo saudável, bons hábitos alimentares, atividades físicas regulares. Ao final do debate, com o consenso de todos, optou-se por iniciar o ano letivo estudando: a "alimentação de um atleta", quais as funções dos alimentos no organismo humano, o que é uma alimentação equilibrada, e quais as consequências de escolhas inadequadas para a alimentação.

A partir dessa primeira definição, algumas hipóteses para o desenvolvimento do projeto curricular foram elaboradas pela professora, com diferentes caminhos que poderiam ser traçados e que iriam ser definidos pela observação e análise constante de cada aula, como resultado das ações e reflexões produzidas pelos alunos e da interpretação realizada pela professora.

As demais escolhas foram, da mesma forma, sendo construídas em conjunto, e resultaram em cinco unidades temáticas de estudo, abordando diferentes conteúdos, conceitos específicos e atividades, conforme Tabela 1.

Cabe ressaltar que o número total de horas aula apresentado na Tabela 1 não corresponde ao total de horas trabalhadas na disciplina de ciências, pois a escola desenvolveu atividades durante o ano letivo, como palestras sobre os temas "gravidez na adolescência", "DSTs", "O primeiro emprego", que coincidiram com o período de aula de ciências. Além disso, não constam, na tabela, as horas/aula utilizadas para avaliações obrigatórias, de acordo com o regimento escolar, e também os momentos em que a professora percebeu a necessidade de parar para conversar com o grupo sobre a proposta que estava sendo desenvolvida, sobretudo no início do ano, quando os alunos ainda não estavam adaptados e, assim como a professora, precisavam dividir suas angústias e dúvidas.

As atividades e o tempo necessário para cada unidade temática de estudo não estavam preestabelecidos quando cada unidade iniciava. Os acontecimentos observados e os materiais obtidos em cada aula foram determinantes para o planejamento dos encontros seguintes, isso porque as hipóteses formuladas pelos alunos, suas reconstruções, as polêmicas e os questionamentos que estes realizavam eram fundamentais para que a professora definisse quais os aspectos que precisariam compor a próxima etapa. Para Coll (1996), o desenvolvimento do currículo é uma das fontes do processo de elaboração, revisão e contínuo enriquecimento do projeto curricular, sendo imprescindível a utilização de informações provenientes de diferentes fontes na sua elaboração, entre elas as que derivam de uma análise psicológica.

Por isso, acredita-se que o professor precisa buscar a interlocução entre teoria e prática para analisar algumas características que são observadas, e que podem contribuir para a tomada de decisões quando organiza estratégias de ensino buscando aprendizagem; e que, além disso, podem ajudar o professor a refletir sobre a melhor forma de realizar intervenções, sobre como interagir em sala de aula, para que os diálogos possibilitem reflexões também por parte dos alunos.

Muitas vezes, na ânsia de que os alunos aprendam, os professores indicam caminhos que facilitam a realização das tarefas: iniciam os processos como se o aluno pudesse completar um raciocínio que ele nem mesmo compreende, desconsideram manifestações diferentes da- 
Silva, D. R.; Pino, J. D.

Tabela 1. Projeto curricular para o ensino de ciências na $8^{a}$ série do Ensino Fundamental.

\begin{tabular}{|c|c|c|c|}
\hline $\begin{array}{l}\text { Unidades } \\
\text { temáticas } \\
\text { de estudo }\end{array}$ & Conteúdos & $\begin{array}{l}\text { Conceitos } \\
\text { Específicos }\end{array}$ & Atividades \\
\hline 1 & $\begin{array}{l}\text { Características } \\
\text { gerais dos } \\
\text { carboidratos, } \\
\text { proteínas e } \\
\text { lipídios } \\
\text { Kcal } \\
\text { Fotossíntese } \\
\text { Digestão dos } \\
\text { carboidratos e } \\
\text { proteínas } \\
\text { Enzimas } \\
\text { Diabetes } \\
\text { Hipoglicemia e } \\
\text { hiperglicemia } \\
\text { Funções do } \\
\text { pâncreas } \\
\text { As células e a } \\
\text { produção de } \\
\text { energia }\end{array}$ & $\begin{array}{l}\text { Reações } \\
\text { químicas } \\
\text { Moléculas } \\
\text { Átomos } \\
\text { Elementos } \\
\text { químicos } \\
\text { Tabela periódica } \\
\text { Modelo atômico } \\
\text { de Dalton }\end{array}$ & $\begin{array}{l}\text { Primeiro contato (em duplas) para diagnosticar os } \\
\text { conhecimentos dos alunos a respeito de alimentos ricos em } \\
\text { carboidratos, lipídios ou proteínas (1h/a). } \\
\text { Aula expositiva envolvendo a fotossíntese e a formação dos } \\
\text { carboidratos (3h/a). } \\
\text { Atividade em grupos sobre a proposição dos modelos ( } 2 \mathrm{~h} / \mathrm{a}) \text {. } \\
\text { Resolução de exercícios em grupos ( } 2 \mathrm{~h} / \mathrm{a}) \text {. } \\
\text { Elaboração de listas de alimentos consumidos pelos alunos } \\
\text { durante uma semana (1h/a). } \\
\text { Visita ao supermercado para pesquisar, nos rótulos dos } \\
\text { alimentos consumidos, sua composição (2h/a). } \\
\text { Resolução de Problemas individualmente (1h/a). } \\
\text { Discussão, no grande grupo, sobre os resultados (2h/a). } \\
\text { Aula expositiva com recursos audiovisuais sobre a digestão } \\
\text { dos carboidratos e proteínas no corpo humano (3h/a). } \\
\text { Estudo de texto sobre o processo de digestão (2h/a). } \\
\text { Atividade em grupo para o estudo da tabela periódica (1h/a). } \\
\text { Discussão, no grande grupo, sobre os resultados (1h/a). } \\
\text { Retomada do primeiro contato individualmente (1h/a). } \\
\text { Estudo de texto sobre diabetes em duplas (2h/a). } \\
\text { Resolução de exercícios sobre o texto (1h/a). } \\
\text { Resolução de problema em duplas (extraclasse). } \\
\text { Discussão no grande grupo, com apresentação dos } \\
\text { resultados (2h/a). }\end{array}$ \\
\hline 2 & $\begin{array}{l}\text { Digestão dos } \\
\text { lipídios }\end{array}$ & $\begin{array}{l}\text { Modelo atômico } \\
\text { Rutherford/Bohr } \\
\text { Tabela periódica } \\
\text { Regra do octeto } \\
\text { Polaridade } \\
\text { Solubilidade } \\
\text { Detergência } \\
\text { *Colesterol } \\
\text { *Pressão } \\
\text { arterial } \\
\text { *Aterosclerose } \\
\text { *Gordura trans } \\
\text { *Vitaminas }\end{array}$ & $\begin{array}{l}\text { Aula expositiva sobre evolução dos modelos atômicos, } \\
\text { regra do octeto, ligações químicas e polaridade das } \\
\text { substâncias ( } 4 \mathrm{~h} / \mathrm{a}) \text {. } \\
\text { Primeiro contato sobre as concepções dos alunos a } \\
\text { respeito de solubilidade, em grupos ( } 2 \mathrm{~h} / \mathrm{a}) \text {. } \\
\text { Atividade prática sobre solubilidade, em grupos, com } \\
\text { elaboração de relatório (2h/a). } \\
\text { Resolução de problema, em grupo (1h/a). } \\
\text { Discussão, no grande grupo, sobre os resultados (1h/a). } \\
\text { Aula expositiva, com recursos audiovisuais, sobre } \\
\text { solubilidade e detergência ( } 2 \mathrm{~h} / \mathrm{a}) \text {. } \\
\text { Estudo de texto sobre digestão dos lipídios no corpo } \\
\text { humano (2h/a). } \\
\text { Resolução de exercícios individualmente (2h/a). } \\
\text { Organização de trabalhos, em grupo, de apresentação } \\
\text { sobre temas* indicados pelos alunos (2h/a). } \\
\text { Apresentação dos trabalhos e elaboração de relatório } \\
\text { avaliando a apresentação dos colegas (5h/a). }\end{array}$ \\
\hline
\end{tabular}

quelas por ele pensadas, como se houvesse um único caminho para se aprender. Esse comportamento dificulta a análise dos acontecimentos e das construções, pois induz os alunos a elaborarem reflexões ou realizarem ações diferentes das que eles realizariam por si mesmos, de acordo com suas estruturas cognitivas. 
Aulas de Ciências na oitava série ...

Tabela 1. continuação

\begin{tabular}{|c|c|c|c|}
\hline $\begin{array}{l}\text { Unidades } \\
\text { temáticas } \\
\text { de estudo }\end{array}$ & Conteúdos & $\begin{array}{l}\text { Conceitos } \\
\text { Específicos }\end{array}$ & Atividades \\
\hline 3 & $\begin{array}{l}\text { Propriedades } \\
\text { dos materiais }\end{array}$ & $\begin{array}{l}\text { Massa } \\
\text { Volume } \\
\text { Densidade } \\
\text { Unidades de } \\
\text { medida } \\
\text { Tabela periódica } \\
\text { Estados físicos } \\
\text { da matéria } \\
\text { Interações } \\
\text { intermoleculares } \\
\text { Compressibilidade, } \\
\text { Expansibilidade }\end{array}$ & $\begin{array}{l}\text { Primeiro contato com o diagnóstico das noções sobre } \\
\text { massa, volume e características visuais dos materiais (2h/a) } \\
\text { Atividade prática com medições de massa e volume de } \\
\text { objetos, em grupo (2h/a). } \\
\text { Resolução de problemas, em grupo (1h/a). } \\
\text { Discussão, no grande grupo, sobre os resultados, com } \\
\text { apresentação de explicações formuladas pelos grupos, } \\
\text { utilizando outros exemplos por eles elaborados (2h/a). } \\
\text { Elaboração de texto abordando as discussões anteriores } \\
\text { (1h/a). } \\
\text { Resolução de Problema individualmente }(2 \mathrm{~h} / \mathrm{a}) \text {. } \\
\text { Discussão dos resultados no grande grupo (1h/a). } \\
\text { Resolução de exercícios em grupo (2h/a). } \\
\text { Resolução de problema em duplas (2h/a). } \\
\text { Discussão dos resultados no grande grupo (1h/a). } \\
\text { Resolução de exercícios individualmente }(2 \mathrm{~h} / \mathrm{a}) \text {. }\end{array}$ \\
\hline 4 & $\begin{array}{l}\text { Sistema excretor } \\
\text { no corpo } \\
\text { humano } \\
\text { Funções do } \\
\text { suor } \\
\text { Sais minerais } \\
\text { Desidratação }\end{array}$ & $\begin{array}{l}\text { Transformações } \\
\text { de estado físico } \\
\text { da matéria } \\
\text { Temperatura } \\
\text { Unidades de } \\
\text { medida } \\
\text { Calor }\end{array}$ & $\begin{array}{l}\text { Primeiro contato como diagnóstico das noções sobre } \\
\text { funções da água no corpo humano e hábitos pessoais (1h/a) } \\
\text { Aula expositiva sobre obtenção e eliminação de água no } \\
\text { corpo humano ( } 2 \mathrm{~h} / \mathrm{a}) \text {. } \\
\text { Estudo de texto sobre sistema excretor ( } 2 \mathrm{~h} / \mathrm{a}) \text {. } \\
\text { Resolução de problemas em trios ( } 2 \mathrm{~h} / \mathrm{a}) \text {. } \\
\text { Discussão sobre os resultados no grande grupo (1h/a). } \\
\text { Elaboração de texto individualmente sobre as discussões } \\
\text { anteriores (1h/a). } \\
\text { Aula expositiva sobre a função dos sais minerais no corpo } \\
\text { humano, formas de obtenção e excreção (2h/a). } \\
\text { Elaboração de cartazes sobre a aula anterior (2h/a). }\end{array}$ \\
\hline 5 & $\begin{array}{l}\text { Esportes, } \\
\text { movimento e } \\
\text { corpo humano }\end{array}$ & $\begin{array}{l}\text { Deslocamento } \\
\text { Trajetória } \\
\text { Movimento e } \\
\text { repouso } \\
\text { Tempo } \\
\text { Unidades de } \\
\text { medida } \\
\text { Velocidade } \\
\text { média } \\
\text { *Anabolizantes } \\
\text { *Anorexia e } \\
\text { Bulimia } \\
\text { *Drogas } \\
\text { alucinógenas, } \\
\text { depressivas e } \\
\text { estimulantes } \\
\text { *Câncer } \\
\text { *Aids }\end{array}$ & $\begin{array}{l}\text { Primeiro contato como diagnóstico das noções de } \\
\text { deslocamento, trajetória, tempo, velocidade, movimento e } \\
\text { repouso (1h/a). } \\
\text { Atividade prática em grupos, com realização de medições } \\
\text { de deslocamento e tempo e elaboração de relatório (1h/a). } \\
\text { Resolução de problema, em grupo (1h/a). } \\
\text { Discussão sobre os resultados no grande grupo (1h/a). } \\
\text { Resolução de problema individualmente (1h/a). } \\
\text { Discussão dos resultados no grande grupo ( } 2 \mathrm{~h} / \mathrm{a}) \text {. } \\
\text { Realização de prática com medições de espaço e tempo } \\
\text { (extraclasse). } \\
\text { Discussão sobre os resultados no grande grupo (1h/a). } \\
\text { Resolução de exercícios ( } 2 \mathrm{~h} / \mathrm{a}) \text {. } \\
\text { Resolução de problemas em trios (2h/a). } \\
\text { Discussão dos resultados no grande grupo (1h/a). } \\
\text { Resolução de exercícios (extraclasse). } \\
\text { Elaboração de apresentação de trabalhos em grupos sobre } \\
\text { temas* definidos pelos alunos (3h/a). } \\
\text { Apresentação dos trabalhos para o grande grupo com } \\
\text { elaboração de relatório a respeito das apresentações dos } \\
\text { colegas (5h/a). }\end{array}$ \\
\hline
\end{tabular}


Silva, D. R.; Pino, J. D.

Assim, a utilização do primeiro contato - atividade em que os alunos precisavam formular explicações a respeito dos conceitos que seriam estudados de acordo com suas concepções iniciais - possibilitou à professora um reconhecimento do que o aluno conhecia ou pensava a respeito do que seria estudado em seguida. Essa estratégia, primeiro contato, somente teve significado e importância na medida em que, a cada aula, novos materiais eram produzidos pelos alunos e analisados pela professora, juntamente com a coleta de dados oriundos da observação e interação constante da professora durante as aulas, que foram gravados em áudio.

O processo de ensino, desta forma, volta-se aos interesses e necessidades dos alunos na medida em que trabalha assuntos relacionados ao seu dia a dia, aos seus conhecimentos, permitindo sua ação, motivando-os a participarem, permitindo, assim, novas assimilações, a partir de questionamentos que os desestabilizem em suas certezas, e que os levem a reflexões e à aprendizagem.

A análise de aspectos sociais e afetivos, relacionados ao contexto da escola e do convívio dos alunos fora da escola, também foi considerada importante e contribuiu para o planejamento e desenvolvimento curricular. Quando se começa um planejamento curricular é preciso: questionar-se sobre como são os alunos que farão parte deste processo, como se pode favorecer a adaptação destes alunos à nova proposta, quais as contribuições que este processo trará a esses alunos, considerando não apenas aspectos cognitivos, mas também aspectos sociais e afetivos envolvidos no contexto da sala de aula.

Segundo Moraes (2004, p. 31),

Ir além do cognitivo pressupõe incluir nos conteúdos a serem trabalhados aspectos afetivos, atitudinais, éticos e de valores. Significa procurar atingir os sujeitos aprendizes em seu todo, não apenas no sentido de seus conhecimentos. Nisso será também implícito um direcionamento para uma qualidade política das aprendizagens.

$\mathrm{Na}$ elaboração da proposta, conhecer os alunos ajudou a professora a organizar questionamentos e situações para que eles pudessem analisar suas posturas de alunos e de cidadãos.

Foram situações importantes para a expressão oral e escrita de opiniões: os momentos de diálogo, possibilitando a exposição de opiniões e o debate entre os alunos ou entre os alunos e a professora, a elaboração de textos e relatórios onde a opinião deles em relação às atividades realizadas precisava ser apresentada, a autoavaliação ou avaliação das apresentações dos colegas. Estas estratégias, inicialmente, não eram consideradas pelos alunos, que muitas vezes não participavam das discussões e não entregavam os trabalhos escritos. Então, a professora passou a questionar estes hábitos, proporcionando momentos em que estes poderiam expressar o porquê da falta de valor para estas atividades. Para os alunos, todas as atividades diferentes da prova não eram consideradas importantes, reflexo de anos de escolaridade onde a prova é o instrumento que determina se os alunos serão aprovados ou não.

A resolução de problemas demonstrou ser uma ótima estratégia para ajudar os alunos a modificarem seu comportamento, na medida em que estes precisavam tomar decisões, defender suas ideias, compará-las com as dos demais nos momentos de debates. Inicialmente, os alunos não realizavam as atividades sem antes perguntar para a professora o que deveriam responder, como se existisse uma única e "verdadeira" resposta, que precisava ser validada 
pela professora. Depois, com o passar do tempo, a compreensão da proposta fez com que os alunos começassem a expor suas ideias a respeito do que era problematizado, sem a preocupação de acertar ou errar, e, então, a solicitação da ajuda da professora passou a ser um momento para discutir hipóteses formuladas pelos grupos ou individualmente.

A cooperação, o respeito à opinião dos colegas, o compromisso com os acordos firmados, a responsabilidade pelas suas atitudes tomadas em relação a si mesmo e com os outros, o comprometimento com as tarefas, foram aspectos que, inicialmente, não faziam parte das características do grupo e que foram sendo construídos durante o desenvolvimento da proposta.

As escolhas realizadas relativas à alimentação, aos hábitos de higiene, aos cuidados com o corpo, a prática de esportes, a prevenção de doenças, o compromisso com a família, com a sociedade escolar, a ética, a solidariedade, começaram a aparecer nos resultados das atividades, nos momentos de discussão, e, sobretudo, nos questionamentos que os alunos passaram a trazer para a sala de aula, demonstrando que a tomada de consciência já estava se refletindo na forma de agir desses sujeitos.

Durante os diálogos em aula muitos alunos passaram a buscar informações a respeito de como prevenir e tratar doenças que acometiam seus familiares, com perguntas como as de dois alunos, por exemplo: "Se meu pai tem colesterol alto eu também terei esse problema na idade dele?" "Minha vó tem triglicerídeos, ela pode transmitir isso para as outras pessoas da família?" Em outro exemplo, pode-se destacar o depoimento de uma aluna que havia sofrido com a anorexia, e que considerou importante compartilhar com os colegas as dificuldades vivenciadas no período em que esteve doente. Além disso, a interação no grupo se modificou, desfazendo os vários "grupinhos" isolados que desprezavam as ideias dos demais, e que, no início do ano letivo, mantinham um ambiente de rivalidade e heteronomia entre os alunos em sala de aula. Termos como "por favor" e "com licença", antes pouco presentes no vocabulário do grupo, tornaram-se constituintes constantes nas falas dos alunos, fortalecendo relações de respeito entre todos.

Neste contexto, com os dados reais de um projeto curricular diferenciado, compreende-se o currículo como práxis, que, de acordo com Freire (1987, p. 92), "sendo reflexão e ação verdadeiramente transformadora da realidade, é fonte de conhecimento reflexivo e criação".

O currículo enquanto processo construído a partir da reflexão das ações dos alunos e da professora torna-se então criação, uma criação única, vinculada ao contexto no qual se desenvolve, e que atende às necessidades dos sujeitos que o compõem.

Da mesma forma que os conteúdos, atividades e a metodologia foram organizadas para construir um projeto curricular diferente do tradicionalmente desenvolvido na escola, as formas de avaliação também precisaram ser planejadas de acordo com o que estava sendo proposto. Para Moraes (2004, p. 33), "a avaliação constitui um elemento central na estruturação de novos currículos".

As exigências da escola, onde a pesquisa foi desenvolvida, no que diz respeito à avaliação, foram as seguintes: a avaliação deveria incluir uma parte da nota a partir de uma análise qualitativa e outra parte quantitativa, sendo obrigatória, segundo o regimento escolar, no mínimo, uma prova escrita e individual. As avaliações eram trimestrais, quando, em cada trimestre, o aluno era avaliado em cem pontos, precisando, ao final do ano, atingir a média cinquenta para ser considerado aprovado. Não havia exigências quanto ao peso da prova, devendo este ser determinado pelo professor. 
Silva, D. R.; Pino, J. D.

Como a proposta buscava respeitar o regimento escolar, foram realizadas algumas provas durante o ano letivo, mas com um peso relativamente baixo se comparado aos outros critérios de avaliação.

Optou-se por realizar a avaliação dos alunos de forma contínua e integrada a todo o processo, pelo acompanhamento constante e análise do comportamento dos alunos em aula e dos materiais por eles produzidos. A metodologia utilizada para a realização das atividades facilitou a análise das aprendizagens dos alunos, pois exigia alunos ativos, responsáveis pela realização das tarefas, e um professor observador, atento ao que estava acontecendo em aula.

Por se tratar de uma proposta com metodologia diferente da tradicionalmente utilizada na escola, inicialmente houve críticas por parte dos alunos, que estavam preocupados com a prova e com o conteúdo que seria cobrado. Os alunos sentiam-se inseguros porque não tinham uma sequência linear de conteúdos no caderno, indicando onde iria iniciar e acabar o que seria avaliado na prova. Com o passar do tempo, a preocupação com as provas diminuiu, resultado do reconhecimento dado, pelos alunos, ao processo que envolvia as atividades em aula como um momento onde havia maior possibilidade de aprendizagem, e que deveria ser considerado na avaliação.

A avaliação contínua tem coerência pedagógica só se a entendemos desde a perspectiva informal com fins formativos, realizada pelos professores dentro das práticas habituais de trabalho e de acompanhamento de tarefas, [...] num clima de comunicação fluente, em que é possível conhecer diretamente o aluno/a sem ter que aplicar-lhe exames desligados do trabalho normal para comprovar suas aquisições, crenças, possibilidades, etc. (GIMENO SACRISTÁN e PÉREZ GÓMEZ, 1998, p. 347)

A cada trimestre, a professora conversava individualmente com cada aluno, apresentando o resultado da avaliação das diferentes atividades realizadas, indicando os aspectos em que o aluno havia obtido melhores resultados e os em que deveria se comprometer mais e melhorar. Nesse momento de conversa, os alunos também se autoavaliavam, concordando ou discordando da professora, até que se chegasse a um resultado comum; eles também avaliavam as atividades, apontando dificuldades e fatos importantes que serviam de informações para que a professora pudesse avaliar o seu trabalho.

Segundo Gimeno Sacristán e Pérez Gómez (1998, p. 341), "só se pode observar a originalidade do aluno/a quando o método e as tarefas concretas de aprendizagem permitem a sua expressão". Desta forma, ao elaborar atividades de acordo com as características cognitivas, sociais e afetivas, a professora estruturou-se para avaliar as mudanças ocasionadas pela proposta pedagógica desenvolvida, comparando resultados em cada uma das etapas vivenciadas. O resultado, na forma de nota, era obtido ao final de cada unidade temática de estudo, depois de várias atividades e intervenções, considerando que cada aluno era comparado consigo mesmo. 


\section{Considerações finais}

A partir do trabalho apresentado, acredita-se que um novo projeto curricular pode ser construído almejando um equilíbrio entre o contexto onde será desenvolvido e as exigências que constituem o sistema de ensino do qual a escola faz parte. Considerar o contexto para planejar e desenvolver o projeto curricular é fundamental para que este seja significativo, tornando a escola uma instituição interessante e importante para o desenvolvimento intelectual e social dos sujeitos que a frequentam. Da mesma forma, respeitar as exigências mínimas de acordo com o regimento escolar ou determinações da secretaria estadual de educação, no caso da escola pública, torna-se necessário para se iniciar o projeto e garantir a sua execução, possibilitando que, posteriormente, a análise e reflexão a respeito dos problemas inerentes a essas exigências resultem em indicações que possam ser questionadas, divulgadas e discutidas.

Entende-se, assim, o professor como um interlocutor entre a realidade da escola e o que é imposto pelo sistema educacional no qual ela está inserida, interlocutor este que busca o equilíbrio a partir da reflexão da sua ação e da ação dos seus alunos, estudando, pesquisando, aprendendo, ensinando, e, assim, valorizando o seu papel de educador dentro da escola.

Cabe ressaltar a importância de um professor crítico, pesquisador, ativo, que acredita na possibilidade de um fazer diferente, pois suas ações podem desencadear uma mudança significativa e de grande valia para o sistema de ensino no qual trabalha; isso porque as contribuições que iniciam isoladamente, dentro do seu componente curricular, podem e devem ser divulgadas para seus colegas professores, e, à medida que os resultados positivos da proposta forem aparecendo, novas possibilidades de parcerias, grupos de pesquisa, elaboração de projetos podem ser organizados e resultarem em modificações mais amplas que atendam a todo o grupo escolar.

Ao planejar e desenvolver um novo projeto curricular, o professor inicia também um processo de reconstrução do papel do aluno, que passa a entender a escola como um lugar interessante, onde ele pode aprender a partir da sua própria ação. Essa reconstrução é fundamental, pois permite: a interação entre alunos e professor, a elaboração de hipóteses, a exposição de ideias, enfim, a produção de materiais que servirão para a análise do professor e serão essenciais para estruturar as escolhas que resultarão no projeto curricular que vai sendo construído enquanto processo, objetivando atender às necessidades e aos interesses de todo o grupo.

Para que o professor consiga compreender o seu fazer e analisar o contexto em que atua, este precisa ter consciência das suas limitações e buscar, na interlocução entre teoria e prática, elementos que o ajudem a refletir sobre seu fazer. Da mesma forma que o professor precisa ser um interlocutor entre o contexto escolar e as exigências exteriores impostas a ele, a interlocução entre teoria e prática torna-se uma necessidade constante, durante todo o processo de construção do projeto curricular, possibilitando a reconstrução do papel do professor, que passa, então, a questionar-se e buscar soluções para seus problemas, indo além do senso comum ou do fazer sem compreender. Estudar deve ser um hábito do educador, pois, somente a partir da pesquisa e do estudo, ele terá condições de planejar e desenvolver, com competência e responsabilidade, um projeto curricular significativo. 
Silva, D. R.; Pino, J. D.

\section{Referências}

ARROYO, M. G. Experiências de inovação educativa: o currículo na prática da escola. In: MOREIRA, A. F. B. (Org.). Currículo: políticas e práticas. Campinas: Papirus, 1999. p. 131-164.

COLL, C. Psicologia e currículo: uma aproximação psicopedagógica à elaboração do currículo escolar. São Paulo: Ática, 1996.

COLLARES, D. Epistemologia genética e pesquisa docente: estudo e conexões no contexto escolar. Lisboa: Instituto Piaget, 2003.

FREIRE, P. Pedagogia do oprimido. 17. ed. Rio de Janeiro: Paz e Terra, 1987.

Pedagogia da autonomia: saberes necessários à prática educativa. Rio de Janeiro: Paz e Terra, 2000.

GIMENO SACRISTÁN, J. O currículo: uma reflexão sobre a prática. 3. ed. Porto Alegre: ArtMed, 2000.

GIMENO SACRISTÁN, J.; PÉREZ GOMES, A. I. Compreender e transformar o ensino. 4. ed. Porto Alegre: ArtMed, 1998.

LOGUERCIO, R. Q.; FERREIRA, M.R.H.; SAMRSLA, V.E.E.; DEL PINO, J.C.

Reinventando a Ciência de oitava série. Porto Alegre: Editora da UFRGS, 2007.

MALDANER, O. A.; ZANON, L. B. Situação de estudo: uma organização do ensino que extrapola a formação disciplinar em Ciências. In: MORAES, R.; MANCUSO, R. (Orgs.).

Educação em Ciências: produção de currículos e formação de professores. Ijuí: Editora Unijuí, 2004. p. 43-64.

MORAES, R. Ninguém se banha duas vezes no mesmo rio: currículos em processo permanente de superação. In: MORAES, R.; MANCUSO, R. (Orgs.). Educação em Ciências: produção de currículos e formação de professores. Ijuí: Editora Unijuí, 2004. p. 15-41.

PORLÁN, R. Constructivismo y escuela. 5. ed. Sevilla: Díada Editora, 1998. (Série fundamentos, 4. Coleccion investigacion y enseñanza)

SCHULTZ, K.; PARHAM, C. Integración del currículum y formación de los enseñantes. In: COLL, C. (Org.). Psicologia genetica y aprendizajes escolares. 4. ed. Madrid: Siglo XXI de España editores, 2002. p. 203-216.

SILVA, T. T. O currículo como fetiche: a poética e a política do texto curricular. Belo Horizonte: Autêntica, 1999.

Artigo recebido em dezembro de 2009 e aceito em maio de 2010.

464

Ciência \&̊ Educação, v. 16, n. 2, p. 447-464, 2010 